\title{
Influência da Tensão de Soldagem e do Gás de Proteção sobre a Correlação entre Indutância e Regularidade da Transferência Metálica na Soldagem MIG/MAG por Curto-Circuito
}

\section{(The Influence of the Welding Voltage and of the Shielding Gas on the Correlation between Inductance and Metal Transfer Regularity in Short-circuiting MIG/MAG Welding)}

\author{
Daniel Souza ${ }^{1}$, Marcelo Lemos Rossi ${ }^{1}$, Flávio Keocheguerians ${ }^{2}$, Vinícius Castanheira do Nascimento ${ }^{2}$, Louriel Oliveira Vilarinho ${ }^{1}$, \\ Américo Scotti ${ }^{1}$ \\ ${ }^{1}$ Universidade Federal de Uberlândia, Faculdade de Engenharia Mecânica,Uberlândia, Minas Gerais, Brasil dsouza@mecanica.ufu. \\ br; marcelo.rossi@mec.ufu.br; vilarinho@mecanica.ufu.br; ascotti@mecanica.ufu.br \\ ${ }^{2}$ Air Products Brasil Ltda, São Paulo, São Paulo, Brasil \\ KEOCHEF2@airproducts.com; NASCIMV1@airproducts.com
}

\begin{abstract}
Resumo
O processo de soldagem MIG/MAG operando no modo de transferência por curto-circuito é largamente utilizado quando se requer baixo aporte de calor. Porém, operando nesse modo, o processo pode apresentar excessiva geração de respingos. Para se minimizar este problema, é necessário atuar na regulagem de seus parâmetros. É sabido que a indutância governa a taxa de variação da corrente, com reflexos sobre a regularidade da transferência da gota por curto-circuito. Mas pouco se conhece sobre o efeito da regulagem da tensão e do uso de gases sobre essa taxa de variação. O objetivo deste trabalho foi avaliar a influência da tensão de soldagem e do gás de proteção na correlação entre a indutância e a regularidade da transferência por curto-circuito na soldagem MIG/MAG de aço carbono. Soldagens foram realizadas varrendo-se a regulagem de tensão em três valores diferentes de regulagem de indutância e com dois gases de proteção, mantendo-se a corrente média constante. Um critério quantitativo foi utilizado para medição da regularidade da transferência. Condições de transferência foram visualizadas por meio de perfilografia sincronizada com filmagem de alta velocidade. Resultados mostraram que a tensão de soldagem e o gás de proteção não influenciaram as taxas de variação da corrente para uma mesma regulagem da indutância, mas que mesmo assim a regularidade do processo é dependente do gás de proteção e da tensão de soldagem.
\end{abstract}

Palavras-chave: MIG/MAG; transferência por curto-circuito; indutância, gás de proteção.

Abstract: The MIG/MAG process operating as short-circuiting is widely used when low heat input is a demand. However, in this operating mode, excessive spattering may occur. To mitigate this problem, it is necessary to act on parameter settings. It is known that inductance governs the current increasing/decreasing rate, reflecting on the short-circuiting transfer regularity. However, little is known about the effect of arc voltage and the gas composition on this rate. Thus, in this work it was pursued the influence of the welding voltage and shielding gas composition in the correlation between inductance and metal transfer regularity in short-circuiting MIG/ $M A G$ carbon-steel welding. Weldments were carried out scanning the voltage settings at three different inductance settings and with two differed shielding gases, using the same current level. A quantitative criterion was employed to assess the metal transfer regularity. Metal transfer conditions were visualized by means of synchronized high-speed filming shadowgraphy. The results showed that voltage and shielding gas do not interfere in the up and down current rate for a same inductance setting, but the regularity of the process is dependent of the shielding gas composition and arc voltage.

Key-words: MIG/MAG; short-circuiting transfer; inductance, shielding gas.

\section{Introdução}

O processo MIG/MAG é um dos processos de soldagem mais utilizados na indústria atualmente. Devido à importância do processo de soldagem para área de fabricação, caracteriza-se a necessidade de se garantir uma boa qualidade dos cordões de solda. Um dos modos operacionais mais utilizados desse processo é o da soldagem por curto-circuito. Com ele, a transferência

(Recebido em 19/04/2011; Texto final em 20/06/2011). de metal se dá basicamente por tensão superficial, quando a gota toca o metal líquido da poça. Este modo de transferência produz uma poça de fusão relativamente pequena, de rápida solidificação, sendo indicado para soldagem de seções finas ou soldagens fora da posição plana. Por causa da importância da aplicação desse tipo de transferência, inúmeros estudos foram realizados com objetivo de entender e aperfeiçoar este tipo de transferência. O principal problema da transferência por curtocircuito é a geração de respingos, que diminui a capacidade de produção, seja devido à perda de material de adição ou à necessidade de dispêndio de recursos para sua retirada. Muitos dos estudos voltados para a redução da geração de respingos baseiam-se na melhoria da estabilidade de curtos-circuitos 
através da correta regulagem dos parâmetros de soldagem.

Dentre os parâmetros que influenciam a transferência por curto-circuito, cita-se a tensão de soldagem, a indutância e o gás de proteção. A influência da tensão de soldagem na regularidade da transferência reside na proporcionalidade desta com o comprimento de arco. Como exemplo da influência do comprimento do arco, pode-se citar um trabalho de Baixo e Dutra [1], no qual se explica o mecanismo de geração de respingos em arcos muito curtos operando no modo de transferência por curto-circuito. Segundo estes autores, em comprimentos de arco muito pequenos, o tempo de arco (tempo em que ocorre a fusão do eletrodo) torna-se muito pequeno. Ao ocorrer o contato com a poça de fusão, a extremidade fundida do eletrodo ainda pode se encontrar em um estágio de fusão impróprio à transferência. Quanto mais prematuro o contato, maior o tempo para que o calor gerado por efeito Joule na ponte de ligação gere sua fusão, promovendo um maior valor de pico da corrente de curto. Ainda segundo estes autores, outro efeito seria uma pressão da extremidade fundida do eletrodo na poça de fusão devido ao constante avanço do arame durante o curto-circuito. Como resultado, há um deslocamento continuado da posição relativa da linha de fusão e geração de uma perturbação excessiva do metal fundido na poça metálica.

Já a indutância é uma propriedade que o circuito elétrico possui de resistir à variação da corrente. Esta propriedade é de extrema importância para o processo MIG/MAG quando operando em curto-circuito, pois o efeito da indutância, que é o de variar a taxa de crescimento/decrescimento da corrente, afeta diretamente o comportamento de destacamento das gotas. No processo por curto-circuito, a regularidade da transferência e, em boa parte, a formação de respingos estão fortemente relacionados ao efeito indutivo. Fontes convencionais de soldagem realizam o controle da indutância por meio de um indutor ligado em série com o arco. Já em fontes eletrônicas, existe um circuito que simula o efeito do indutor, ou seja, age de forma a variar a taxa de subida e descida da corrente. Em soldagem, não é possível se basear somente numa regulagem de um valor de indutância (por exemplo, em Henry) na fonte, pois a indutância do sistema não depende só do circuito da fonte, mas também do próprio arco, cabos, etc.. Por este motivo, as fontes possuem regulagens de posições de indutância e não valores de indutância. Então, a melhor forma de se fazer referência à indutância de um equipamento é pelo termo "efeito indutivo", ou seja, pelas taxas de crescimento e decrescimento da corrente para uma dada condição de soldagem. A Figura 1 e a Tabela 1 mostram o efeito indutivo (di/dt) em função da posição regulagem da indutância para duas fontes diferentes, as quais possuem escalas díspares de regulagem. Observa-se que não só o valor de di/dt se torna diferente para uma mesma regulagem, mas também o gradiente de variação de di/dt. Isto suporta a idéia do uso do efeito indutivo e não do valor de indutância fornecido por diferentes equipamentos quando se quer comparar regulagens de parâmetros.

Finalmente, o gás de proteção afeta a regularidade da transferência pela mudança promovida no comprimento do arco e na tensão superficial do metal líquido. Zielinska et al [4] variaram a quantidade de $\mathrm{CO}_{2}$ em argônio para mostrar a influência do

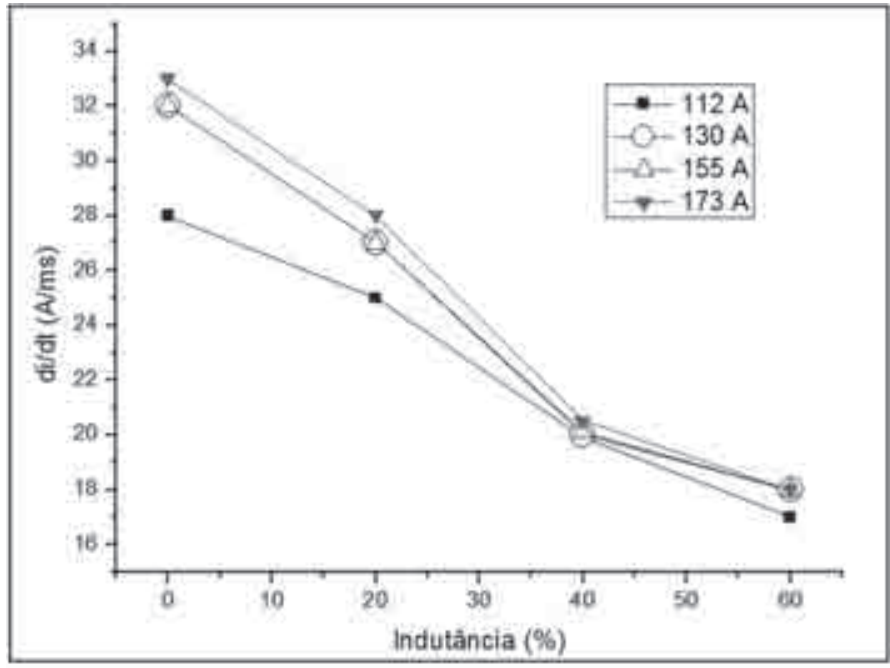

Figura 1 - Efeito da regulagem de indutância nas taxas de variação da corrente em função da corrente de soldagem, para uma fonte microprocessada multiprocesso da marca Miller, modelo MAXTRON 450, utilizando arame tubular E70C-6M de 1,2 mm de diâmetro e gás de proteção $\mathrm{Ar}+25 \% \mathrm{CO}_{2}$ [2]

$\mathrm{CO}_{2}$ na tensão do arco (Figura 2). Estes resultados são devidos a uma maior necessidade de energia para manutenção do arco com $\mathrm{CO}_{2}$, quando comparado com Ar, provavelmente por causa da sua maior capacidade de troca de calor. Misturas com de dióxido de carbono, comumente argônio entre 18 a 25\% de CO2, são usadas para transferência por curto-circuito. Porém, Stenbacka e Persson [5] demonstram que mais do que $15 \%$ de $\mathrm{CO}_{2}$ no gás de proteção desestabiliza a transferência metálica e aumenta a quantidade de respingos. Resultados de Aqusa e Yamauchi [6] apud STENBACKA; PERSSON [5] também mostram que o aumento do teor de $\mathrm{CO}_{2}$ em Ar aumenta a geração de respingos, ou seja, torna o processo menos regular (Figura 3 ).

Tabela 1 - Efeito da regulagem de indutância nas taxas de variação da corrente para uma fonte eletrônica multiprocesso (fabricante IMC, modelo Inversal 300), utilizando o arameeletrodo ER 4043 de diâmetro de 1,0 mm e gás de proteção Ar puro [2]

\begin{tabular}{|c|c|}
\hline Posição de regulagem da indutância & $\mathrm{di} / \mathrm{dt}(\mathrm{A} / \mathrm{ms})$ \\
\hline 0 & 136,08 \\
\hline 2,5 & 34,34 \\
\hline 5 & 26,49 \\
\hline 7,5 & 18,68 \\
\hline 10 & 14,52 \\
\hline
\end{tabular}




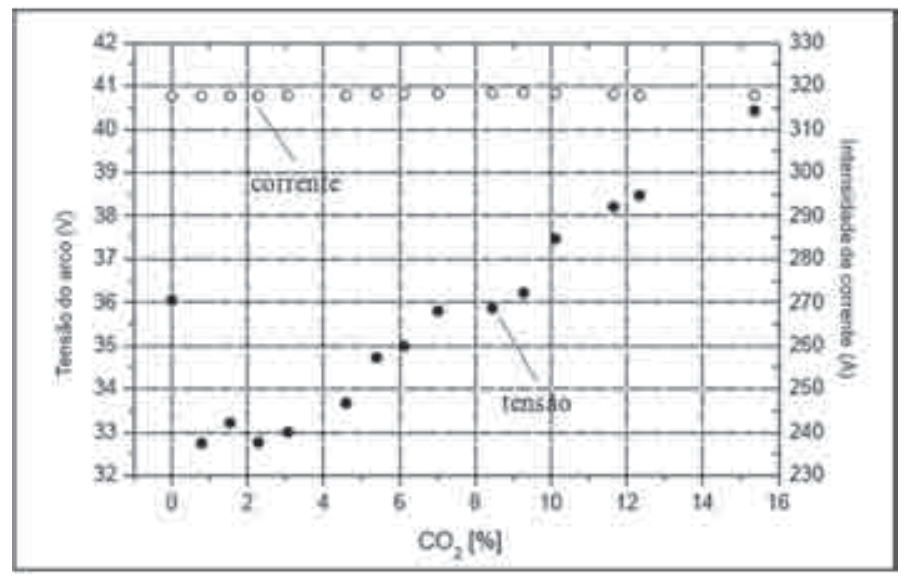

Figura 2 - Influência da adição de $\mathrm{CO} 2$ em Ar na tensão de soldagem para o processo operando no modo corrente constante com velocidade de alimentação de $9 \mathrm{~m} / \mathrm{min}$ e DBCP de $20 \mathrm{~mm}$, na soldagem de aço carbono ([4] traduzida)

Em um trabalho prévio [6], em que os autores do presente artigo tentaram avaliar a influência da regulagem da tensão de soldagem sob diferentes gases de proteção sobre a regularidade da transferência, observou-se que a regulagem da indutância interferia nos resultados. E que esta interferência não assumia um padrão de comportamento, sendo diferente para cada gás de proteção em função da tensão, como ilustra a Figura 4. Esta particularidade ainda não é discutida de forma mais abrangente na literatura técnica. Por exemplo, Dutra [7] estudou em seu trabalho o efeito das taxas de subida e descida da corrente sobre a qualidade do cordão utilizando os gases de proteção Ar $+25 \% \mathrm{CO}_{2}$ e $\mathrm{CO}_{2}$ puro. Foi utilizada uma fonte que permitia a regulagem do efeito indutivo da taxa de subida e da taxa de descida de forma separada. Este autor mostrou que a taxa de subida praticamente não influi na qualidade do cordão (desde que o valor seja de aproximadamente $60 \mathrm{~A} / \mathrm{ms}$ ), independente do gás utilizado, e que a taxa de descida da corrente deve ser maior quando se usa a mistura com maior teor de $\mathrm{CO}_{2}$. Porém, no

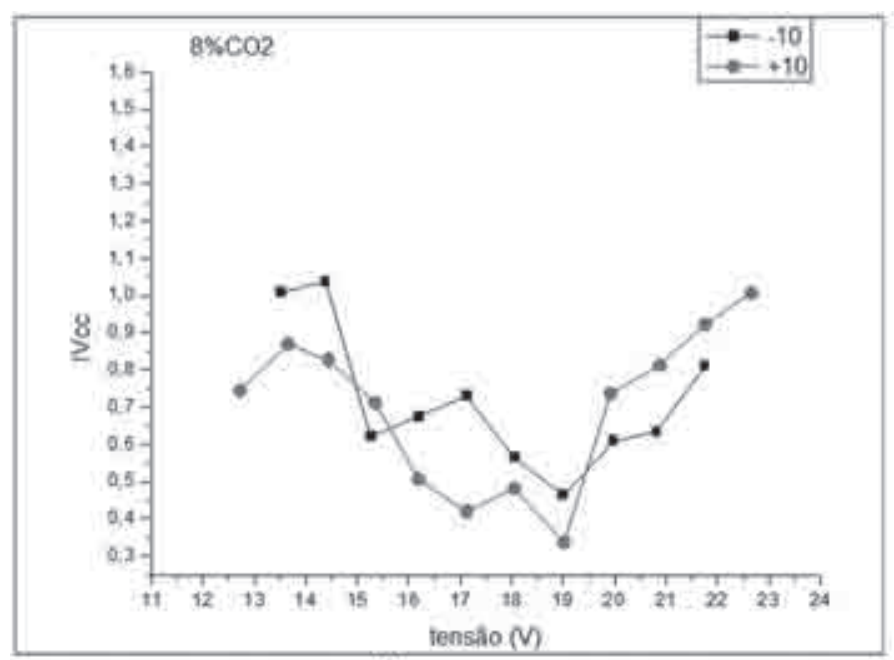

(a)

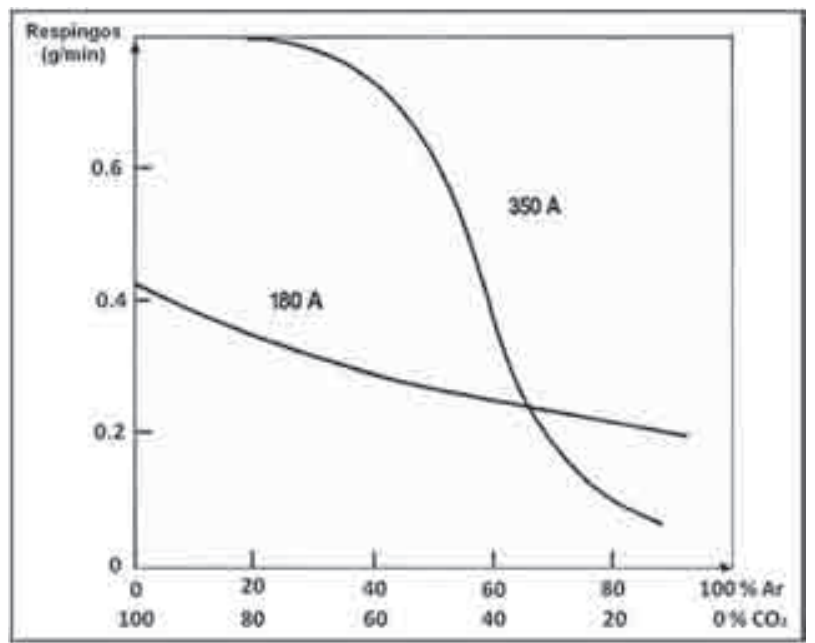

Figura 3 - Efeito do teor de $\mathrm{CO}_{2}$ no gás de proteção sobre a taxa de geração de respingos, para soldagem MIG/MAG convencional utilizando arame-eletrodo maciço ([5] traduzida)

trabalho em questão, o autor não variou a tensão de soldagem, negligenciando o efeito deste parâmetro sobre a relação entre o efeito indutivo e a qualidade do cordão.

Desta forma, neste trabalho se propõe a avaliar, de forma mais sistemática, a correlação entre indutância e regularidade da transferência metálica na soldagem MIG/MAG por curtocircuito, sob a influência da tensão de soldagem e do gás de proteção.

\section{Metodologia e Procedimentos Experimentais}

Para procurar entender os fenômenos relacionados com a regularidade de transferência metálica frente à variação da indutância, procurou-se visualizar as mesmas através de filmagens de alta velocidade e aquisição de sinais elétricos das soldagens com diferentes parâmetros. Experimentos foram realizados variando-se a tensão de soldagem em três níveis, de forma a se obter comprimentos de arco curtos, médios e longos,

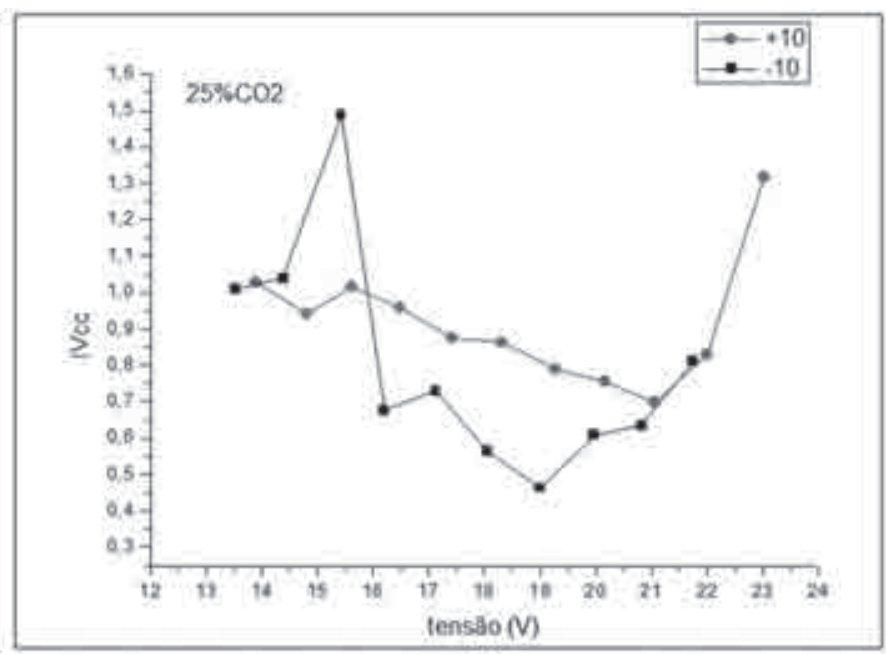

(b)

Figura 4 - Índice de regularidade em função da tensão de soldagem para as posições de regulagem do efeito indutivo da fonte, utilizando como gás de proteção a mistura em (a) $\mathrm{Ar}+8 \% \mathrm{CO}_{2}$ e em (b) $\mathrm{Ar}+25 \% \mathrm{CO}_{2}$ [6] 
usando-se duas diferentes misturas de $\mathrm{Ar}$ e $\mathrm{CO}_{2}$ para proteção, mantendo-se a regulagem do fator indutivo na posição média (zero). Depois, na condição de arco médio, variou-se a posição de regulagem para os valores máximo (+10) e mínimo (-10), usando-se as mesmas duas misturas de gases de proteção.

As soldagens foram realizadas como simples deposição sobre chapa em chapas de teste de aço ao carbono com dimensões 9,5 x 38 x $200 \mathrm{~mm}$. A tocha foi inclinada de forma a que a soldagem se desse puxando com $15^{\circ}$. A fonte de soldagem utilizada foi do tipo eletrônica inversora da marca Lincoln Electric modelo Power Wave 455M/STT (lembrando-se que a tecnologia de fabricação da fonte pode interferir nos resultados) regulada para operar no modo tensão constante sem sinergismo (programa 5). As filmagens foram realizadas a uma taxa de 2000 quadros por segundo, utilizando-se da técnica de perfilografia sincronizada, já descrita em inúmeros trabalhos, como por exemplo Souza; Resende; Scotti [8]. A aquisição dos sinais elétricos foi realizada com um sistema com taxa de aquisição regulada para $5 \mathrm{kHz}$ e tempo de aquisição de $5 \mathrm{~s}$. A Tabela 2 apresenta os parâmetros de regulagem e condições de soldagem utilizadas.

\section{Resultados e Discussão}

Tabela 2 - Parâmetros de regulagem dos testes

\begin{tabular}{|c|c|c|c|c|c|c|}
\hline Código do teste & $\begin{array}{c}\text { Tensão de } \\
\text { regulagem }(\mathrm{V})\end{array}$ & $\begin{array}{c}\text { Velocidade de } \\
\text { alimentação }(\mathrm{m} / \mathrm{mim})\end{array}$ & $\begin{array}{c}\text { Velocidade de } \\
\text { soldagem }(\mathrm{cm} / \mathrm{min})\end{array}$ & $\begin{array}{l}\mathrm{DBCP} \\
(\mathrm{mm})\end{array}$ & Gás de proteção & $\begin{array}{c}\text { Posição de regulagem } \\
\text { do efeito indutivo }\end{array}$ \\
\hline Exp11 & 22,0 & 2,76 & 27 & 12 & $\mathrm{Ar}+8 \% \mathrm{CO}_{2}$ & 0 \\
\hline Exp15 & 17,7 & 2,76 & 27 & 12 & $\mathrm{Ar}+8 \% \mathrm{CO}_{2}$ & 0 \\
\hline Exp2 & 14,0 & 2,76 & 27 & 12 & $\mathrm{Ar}+8 \% \mathrm{CO}_{2}$ & 0 \\
\hline Exp43 & 25,0 & 2,71 & 27 & 12 & $\mathrm{Ar}+25 \% \mathrm{CO}_{2}$ & 0 \\
\hline Exp36 & 21,3 & 2,71 & 27 & 12 & $\mathrm{Ar}+25 \% \mathrm{CO}_{2}$ & 0 \\
\hline Exp49 & 17,0 & 2,71 & 27 & 12 & $\mathrm{Ar}+25 \% \mathrm{CO}_{2}$ & 0 \\
\hline Exp4 & 17,7 & 2,76 & 27 & 12 & $\mathrm{Ar}+8 \% \mathrm{CO}_{2}$ & +10 \\
\hline Exp5 & 17,7 & 2,76 & 27 & 12 & $\mathrm{Ar}+8 \% \mathrm{CO}_{2}$ & -10 \\
\hline Exp6 & 21,3 & 2,71 & 27 & 12 & $\mathrm{Ar}+25 \% \mathrm{CO}_{2}$ & +10 \\
\hline Exp7 & 21,3 & 2,71 & 27 & 12 & $\mathrm{Ar}+25 \% \mathrm{CO}_{2}$ & -10 \\
\hline
\end{tabular}

DBCP = Distância bico de contato-peça

Tabela 3 - Resultados das análises dos sinais elétricos dos testes e cálculo do índice de regularidade

\begin{tabular}{|c|c|c|c|c|c|c|}
\hline Código do teste & U média $(\mathrm{V})$ & I média $(\mathrm{A})$ & tcc $(\mathrm{ms})$ & Ip $(\mathrm{A})$ & Fcc $(\mathrm{Hz})$ & IVcc \\
\hline Exp11 & 18,7 & 143 & $8,7 \pm 1,9$ & $291 \pm 39$ & 8,2 & $=$ \\
\hline Exp15 & 14,8 & 146 & $7,1 \pm 1,8$ & $217 \pm 14$ & 28,2 & 0,87 \\
\hline Exp2 & 11,1 & 142 & $19,7 \pm 6,9$ & $395 \pm 171$ & 18,2 & 0,97 \\
\hline Exp43 & 21,2 & 134 & $9,3 \pm 2,9$ & $340 \pm 24$ & 3,5 & - \\
\hline Exp36 & 17,9 & 147 & $7,5 \pm 2,2$ & $270 \pm 31$ & 19,7 & 1,22 \\
\hline Exp49 & 12,6 & 147 & $13,8 \pm 6,8$ & $263 \pm 111$ & 28,5 & 1,36 \\
\hline Exp4 & 14,9 & 143 & $6,5 \pm 1,2$ & $263 \pm 22$ & 27,7 & 0,59 \\
\hline Exp5 & 14,8 & 146 & $8,1 \pm 2,1$ & $199 \pm 9$ & 25 & 1,10 \\
\hline Exp6 & 17,9 & 141 & $6,8 \pm 2,0$ & $334 \pm 37$ & 17 & 1,05 \\
\hline Exp7 & 17,9 & 145 & $10,3 \pm 3,4$ & $222 \pm 17$ & 14,2 & 1,23 \\
\hline
\end{tabular}

$U=$ tensão $;=$ corrente $;$ tcc = tempo em curto-circuito $;$ Ip = corrente de pico; Fcc = freqüencia de curto-circuito, IVcc = índice de regularidade 

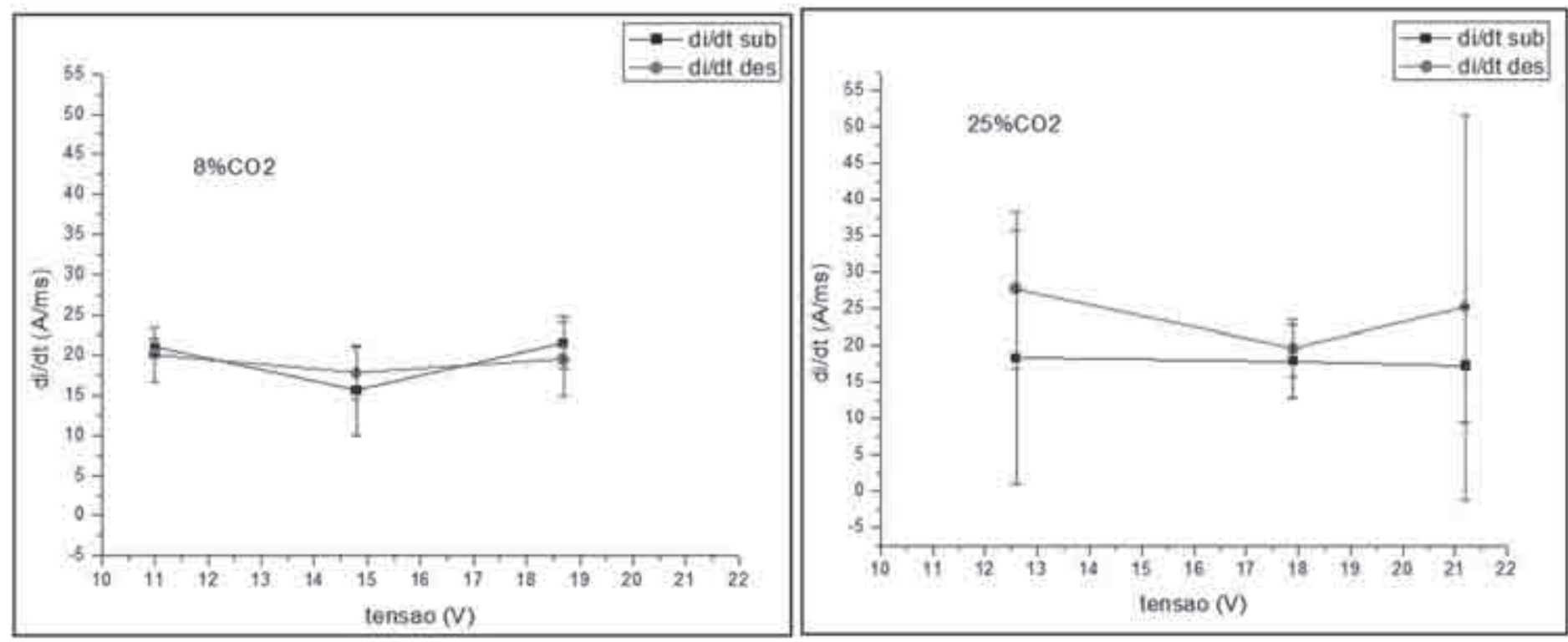

Figura 5 - Variação das taxas de subida e descida da corrente em função da variação da tensão de soldagem para dois gases de proteção, posição de regulagem do efeito indutivo igual a zero (posição média)

A Figura 5 apresenta os valores da taxa de subida e descida da corrente para os testes Exp11, Exp15, Exp2, Exp43, Exp36, Exp49, onde se variou a tensão de soldagem em três níveis para dois gases de proteção diferentes. Pode se observar que se mantendo a posição de regulagem da indutância em zero e variando-se a tensão de soldagem, levando-se em consideração o desvio padrão, as taxas de subida e descida da corrente não foram afetadas pela variação da tensão. Também é interessante observar que o desvio padrão é maior quando se usa $\mathrm{Ar}+$ $25 \% \mathrm{CO}_{2}$, provavelmente devido ao maior nível de irregularidade do processo, conforme apontado pelo IVcc.

As Figuras 6 a 11 apresentam a visualização da transferência metálica através de imagens sincronizadas com os oscilogramas de corrente e tensão para os testes em que se variou a tensão (comprimento de arco) para os dois gases de proteção utilizados. No geral, pode-se observar que para os testes em que se usavam comprimentos de arco curtos (Exp2 e Exp49) ou longos (Exp11 e Exp43), independente do gás utilizado, a poça de fusão oscilava mais do que quando se utilizavam arcos com comprimento médio (Exp15 e Exp36). Nesta figuras, também se observa que a oscilação da poça foi mais pronunciada utilizando-se gás de proteção $\mathrm{Ar}+25 \% \mathrm{CO}_{2}$, além da observação da formação de respingos nos casos com maior oscilação da poça. Estes resultados apóiam resultados obtidos em trabalhos anteriores $[6,9,10]$, os quais procuraram validar a relação do índice de regularidade proposto com a estabilidade do processo operando em curto-circuito. Além disso, os resultados mostram que para baixos níveis de regularidade (regulagens de tensão alta ou baixas demais), apesar do efeito indutivo estatisticamente ser o mesmo, as correntes de pico (Tabela 3) alcançam por vezes valores muito altos, prejudicando profundamente a transferência no momento em que a gota se transfere (visualizadas nas filmagens e ilustradas nas fotografias). Também se observa que na condição de arcos curtos (baixa tensão) as correntes de pico apresentam altos valores de desvio padrão. Tais anomalias na variação corrente durante o curto-circuito são provavelmente fruto de condições inadequadas de comprimento de arco (valores inadequados de tensão) e devem ser as principais responsáveis pelas oscilações da poça mostradas nas fotografias.

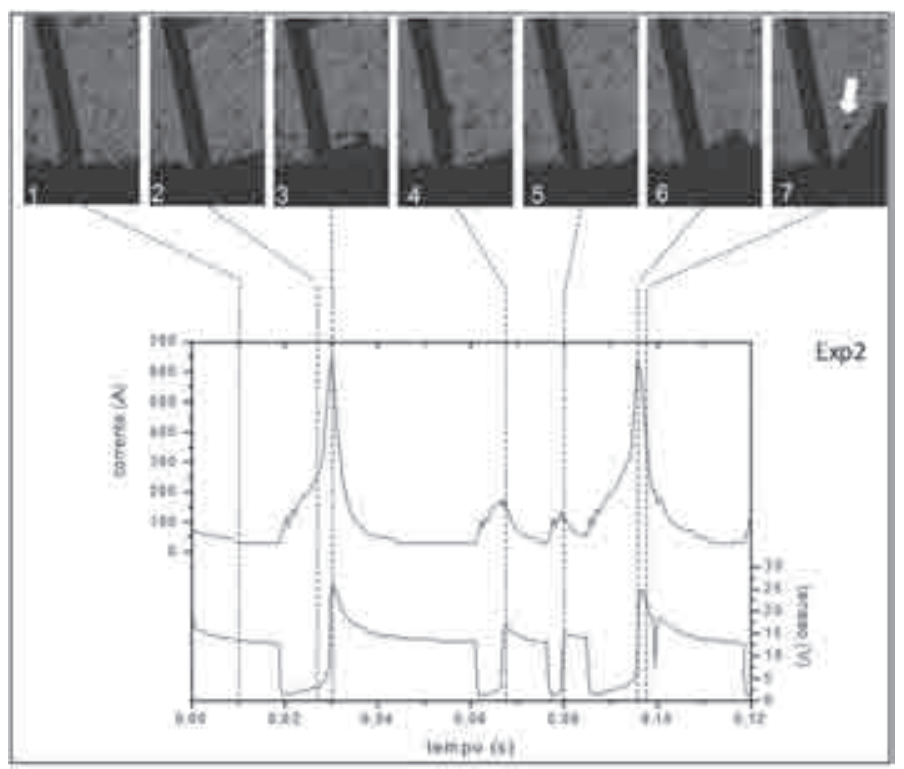

Figura 6 - Transferência metálica sincronizada com os sinais elétricos: seta mostrando respingo sendo ejetado - arco curto $8 \% \mathrm{CO}_{2}$ (U média de $11,1 \mathrm{~V}$ e I média de $142 \mathrm{~A}$ ) 


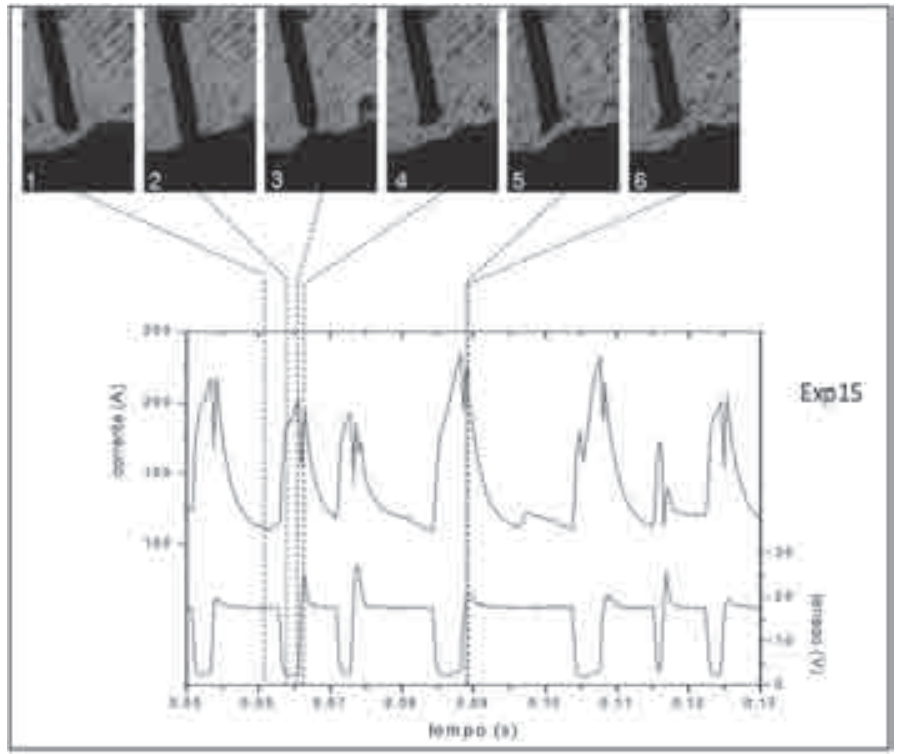

Figura 7 - Transferência metálica sincronizada com os sinais elétricos - arco médio - $8 \% \mathrm{CO}_{2}$ (U média de $14,8 \mathrm{~V}$ e I média de $146 \mathrm{~A})$

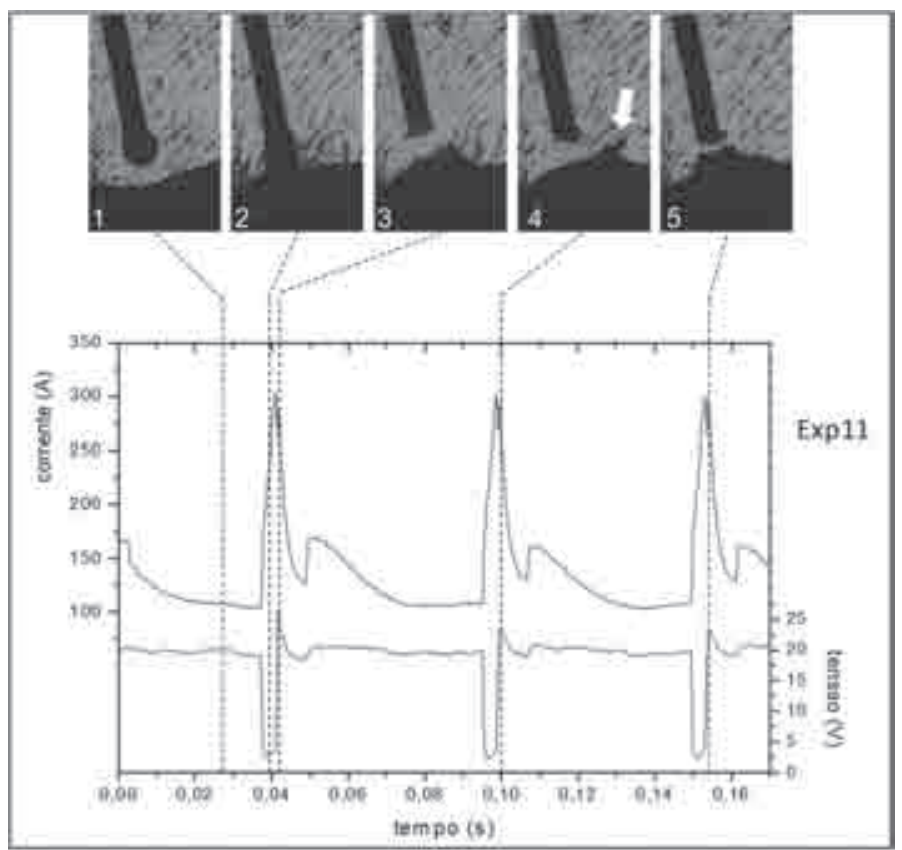

Figura 8 - Transferência metálica sincronizada com os sinais elétricos: seta mostrando formação de respingo - arco longo $8 \% \mathrm{CO}_{2}$ (U média de $18,7 \mathrm{~V}$ e I média de $143 \mathrm{~A}$ )

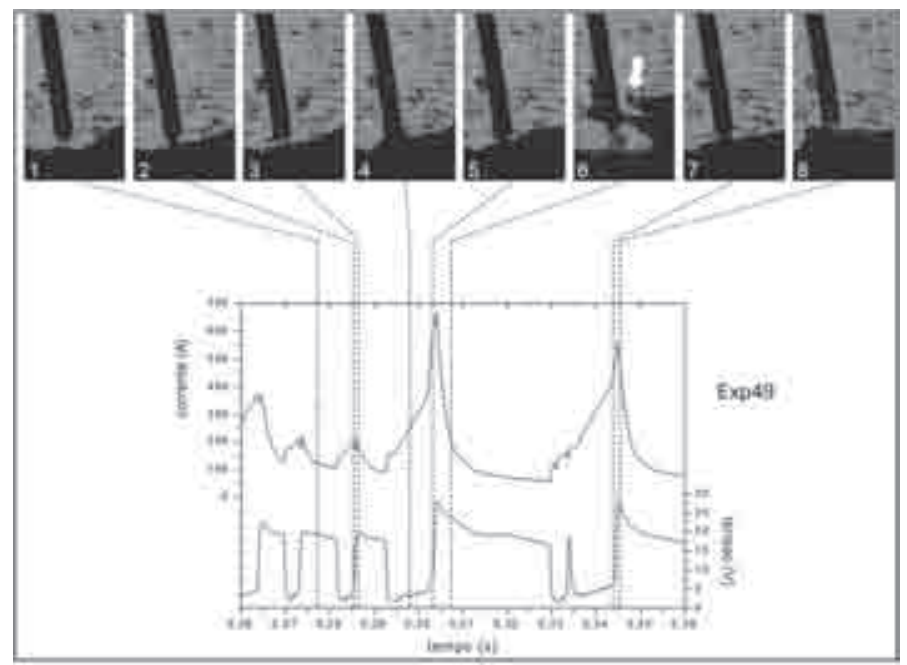

Figura 9 - Transferência metálica sincronizada com os sinais elétricos - seta mostrando respingo sendo ejetado - arco curto - 25\% $\mathrm{CO}_{2}$ (U média de $12,6 \mathrm{~V}$ e I média de 147 A)

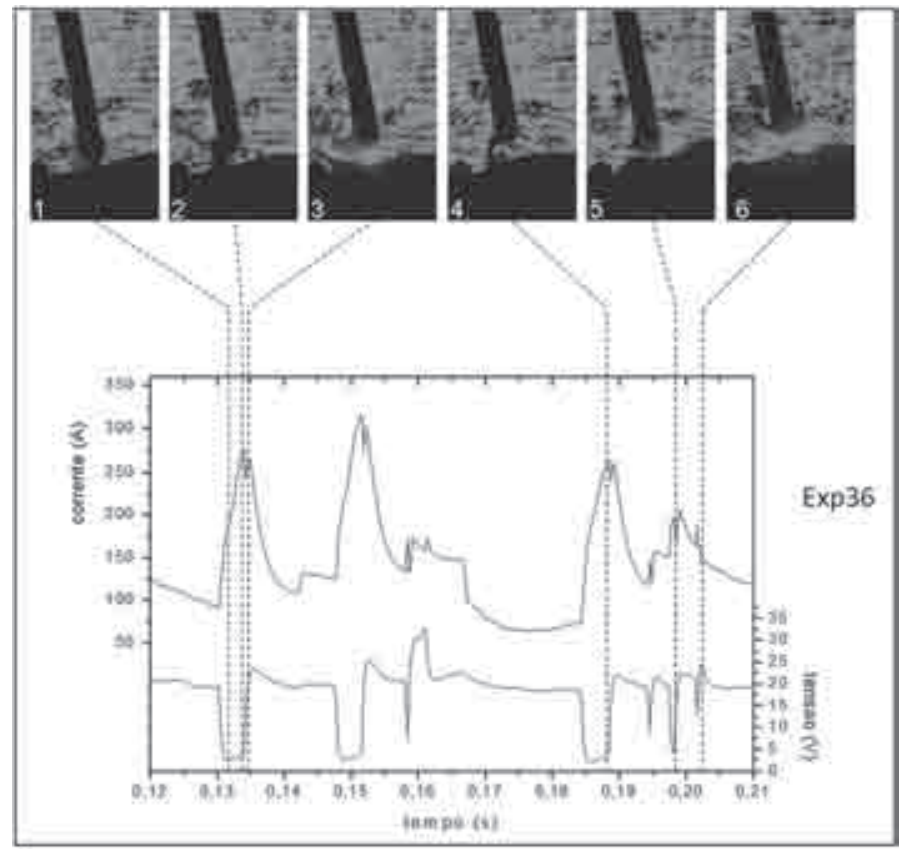

Figura 10 - Transferência metálica sincronizada com os sinais elétricos - arco médio - 25\% $\mathrm{CO}_{2}$ (U média de $17,9 \mathrm{~V}$ e I média de $147 \mathrm{~A}$ ) 


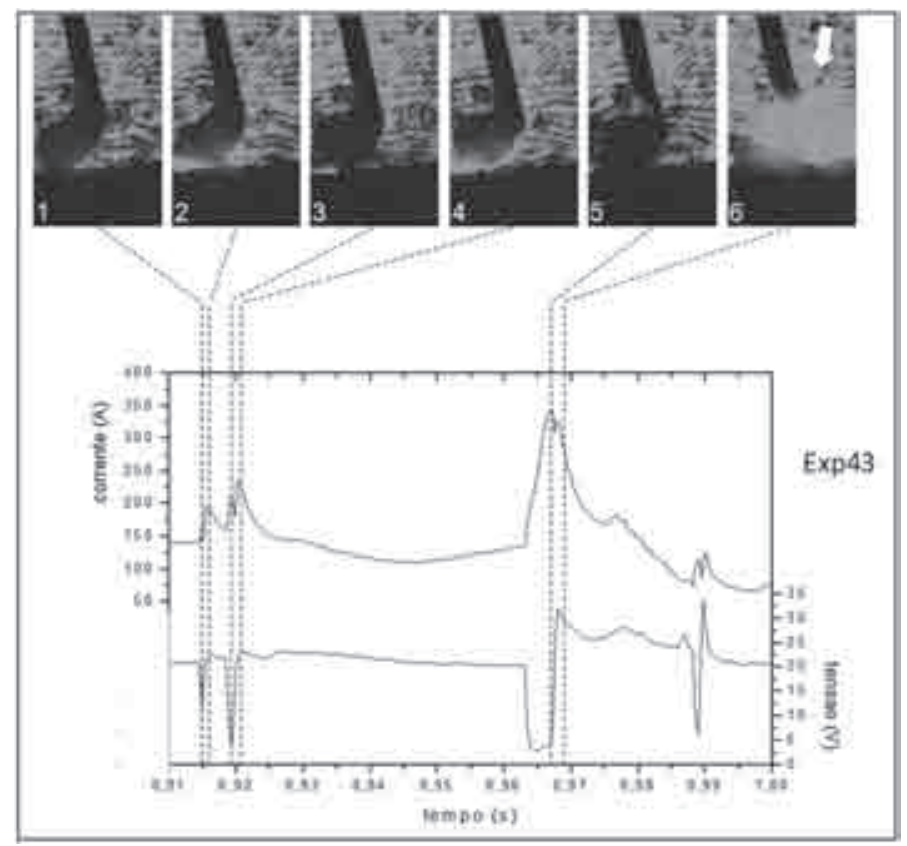

Figura 11- Transferência metálica sincronizada com os sinais elétricos: seta mostrando respingo sendo ejetado - arco longo $25 \% \mathrm{CO}_{2}$ (U média de $21,2 \mathrm{~V}$ e I média de $134 \mathrm{~A}$ )
A Figura 12 apresenta os valores das taxas de subida e descida da corrente em função da posição de regulagem na fonte para os testes Exp4 e Exp5 (utilizando $\mathrm{Ar}+8 \% \mathrm{CO}_{2}$ ) e Exp6 e Exp7 (utilizando $\mathrm{Ar}+25 \% \mathrm{CO}_{2}$ ). Esta figura mostra que a mudança na posição de regulagem realmente altera as taxas de subida e descida da corrente. Pode-se observar na Tabela 3 que os testes realizados nas posições de regulagem que produziam taxas de variação da corrente mais altas (Exp4 e Exp6), apresentaram também melhores índices de regularidade. Observando-se as Figuras 13 a 16, pode-se perceber que esses testes apresentaram menos curtos-circuitos incipientes, a saber, Exp4 sem curtos incipientes e Exp6 com freqüência de curtos incipientes de $2 \mathrm{~Hz}$, contra 7,5 Hz para o Exp5 e 4,75 Hz para o Exp7. É importante observar que apesar dos testes com maiores taxas de variação da corrente apresentarem melhores índices de regularidade, pelas fotografias observa-se que a transferência ocorria de forma mais abrupta e a poça tinha maiores oscilações (maiores correntes de pico). Este resultado indica que nem sempre transferências com maiores correntes de pico implicam em irregularidades na transferência metálica.

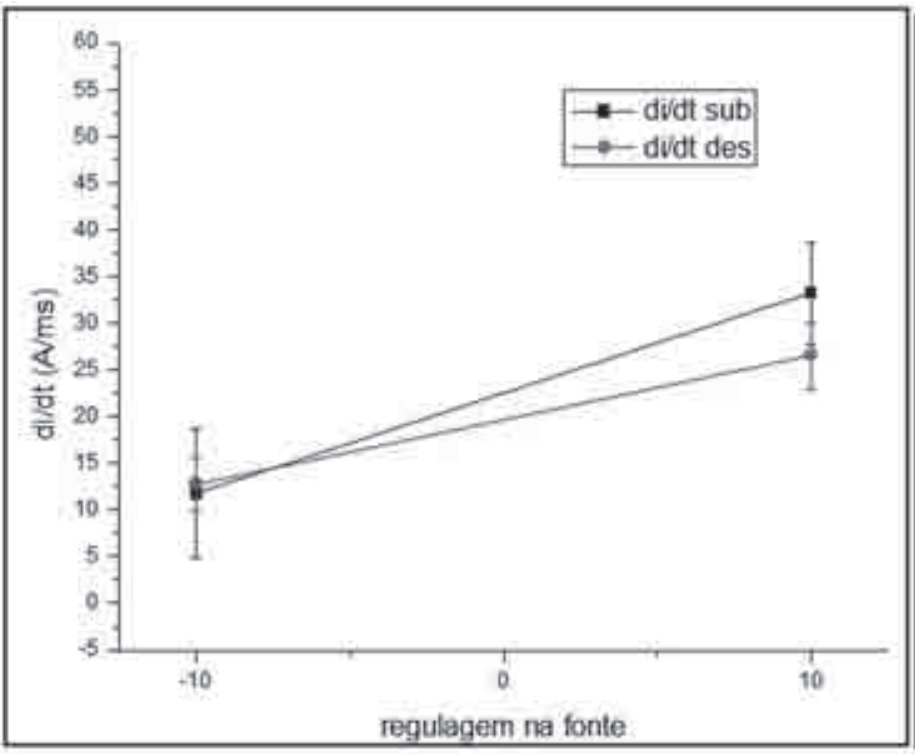

$\mathrm{Ar}+8 \% \mathrm{CO}_{2}$

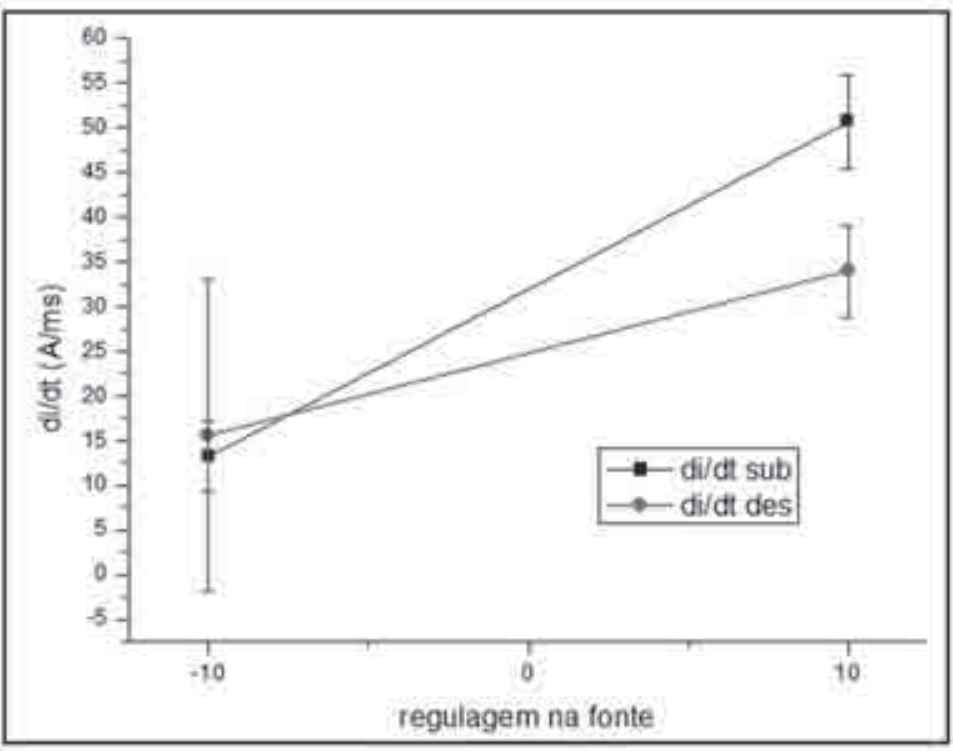

$\mathrm{Ar}+25 \% \mathrm{CO}_{2}$

Figura 12 - Variação das taxas de subida e descida da corrente em função da variação da posição de regulagem do efeito indutivo para dois gases de proteção ( $\mathrm{U}$ média $=15 \mathrm{~V}$ para $\mathrm{Ar}+8 \% \mathrm{CO}_{2}$ e $18 \mathrm{~V}$ para $\mathrm{Ar}+25 \% \mathrm{CO}_{2}$ ) 


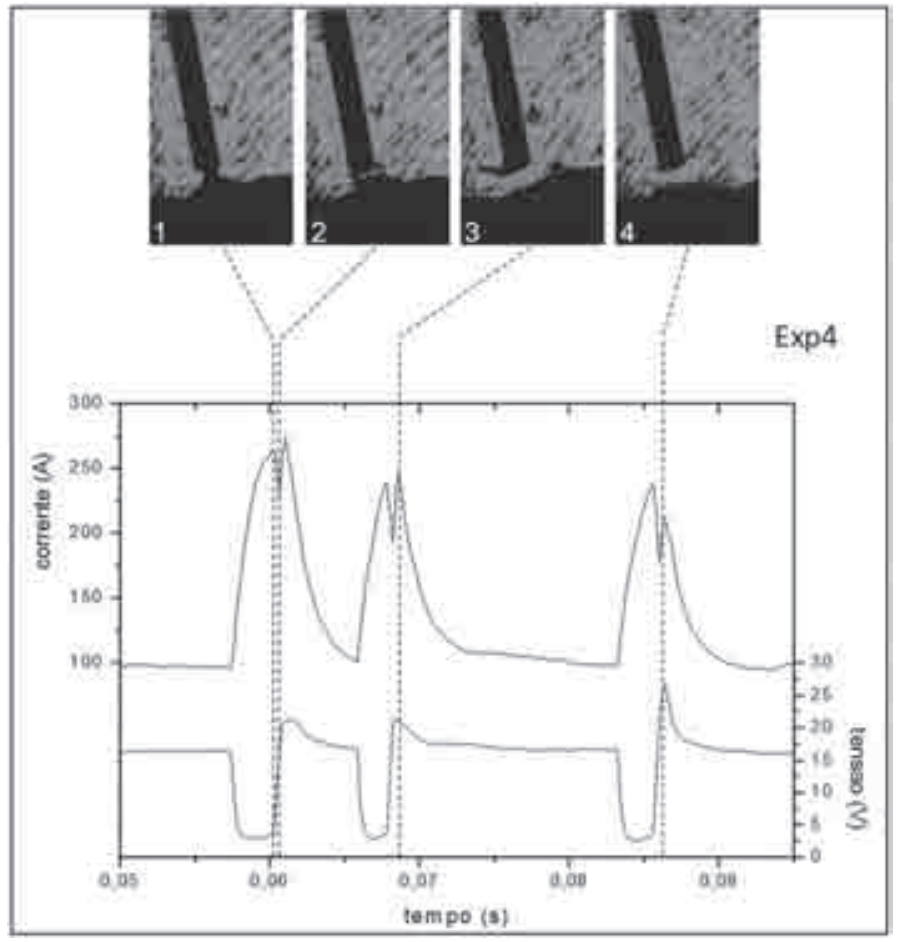

Figura 13 - Transferência metálica sincronizada com os sinais elétricos - maior taxa de variação da corrente $-8 \% \mathrm{CO}_{2}(\mathrm{U}$ média de $14,9 \mathrm{~V}$ e I média de 143 A)

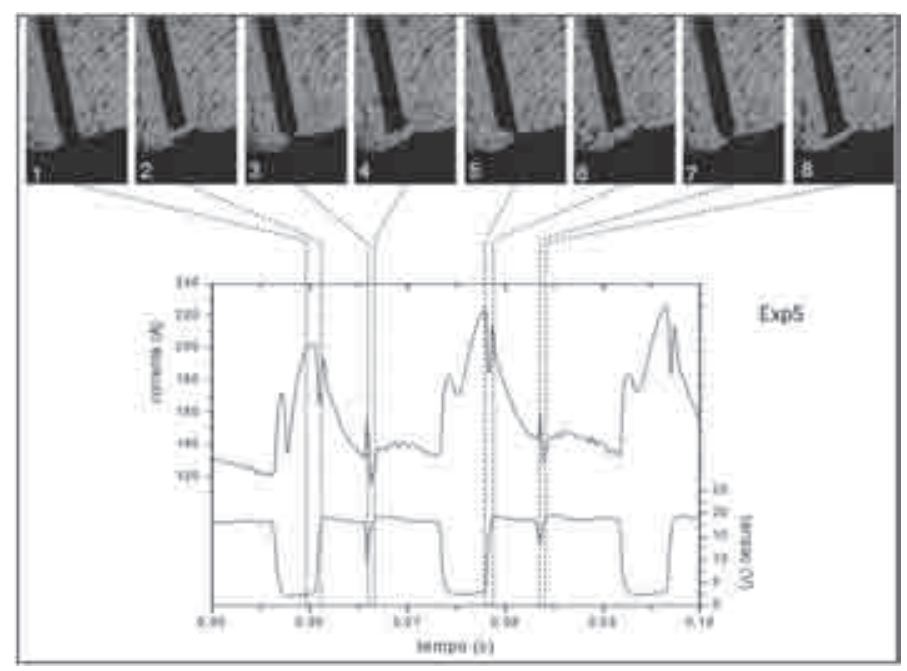

Figura 14 - Transferência metálica sincronizada com os sinais elétricos - menor taxa de variação da corrente $-8 \% \mathrm{CO}_{2}(\mathrm{U}$ média de 14,8 V e I média de 146 A)

\section{Conclusões}

Para as condições e parâmetros de soldagem utilizados neste trabalho, pode-se concluir que:

- A regularidade do processo é depende do gás de proteção $e$ da tensão de soldagem, mas esses parâmetros não afetam as taxas de subida e descida da corrente quando a posição de regulagem do efeito indutivo é mantida fixa (possível em

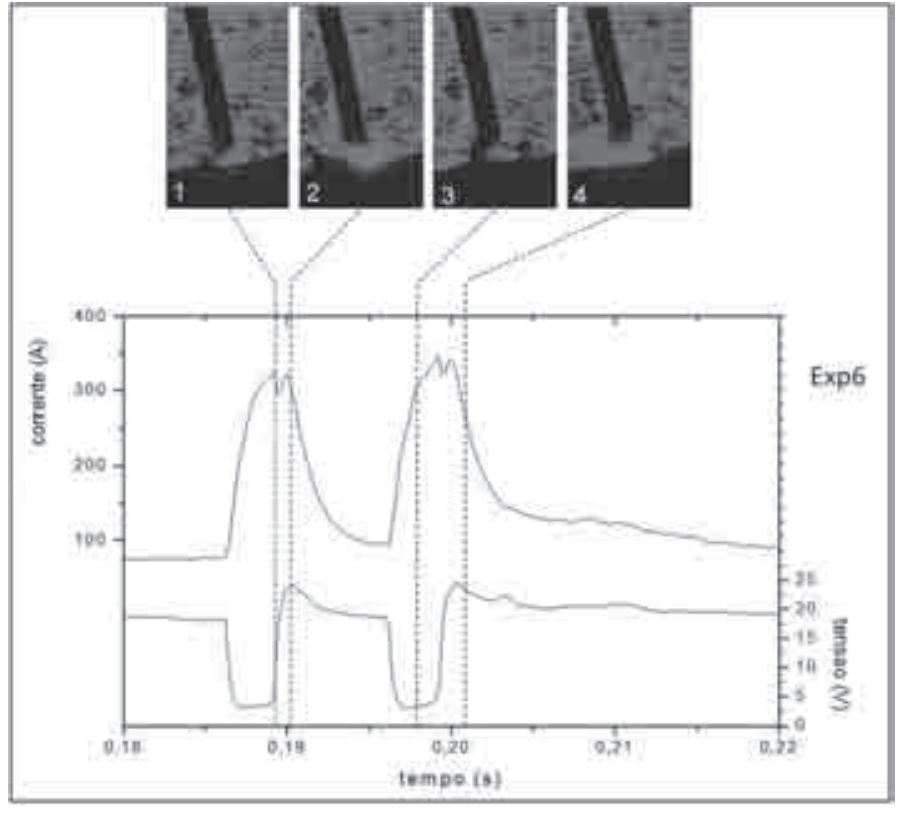

Figura 15 - Transferência metálica sincronizada com os sinais elétricos - maior taxa de variação da corrente $-25 \% \mathrm{CO}_{2}(\mathrm{U}$ média de $17,9 \mathrm{~V}$ e I média de 141 A)

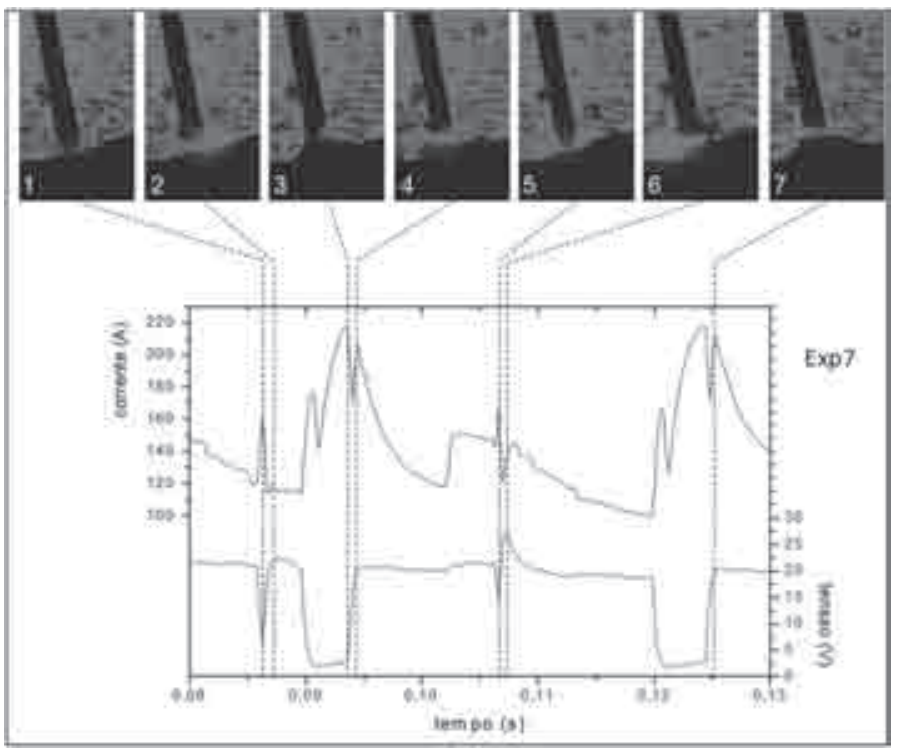

Figura 16 - Transferência metálica sincronizada com os sinais elétricos - menor taxa de variação da corrente $-25 \% \mathrm{CO}_{2}(\mathrm{U}$ média de $17,9 \mathrm{~V}$ e I média de 145 A)

fontes eletrônicas);

- Por outro lado, as correntes de pico e os tempos de curtocircuito se afastam muito da média em situações onde a transferência está instável (transferências irregulares que acontecem em comprimentos de arco curtos ou longos demais), provocando grandes oscilações na poça e respingos;

- Regulagens que promovem taxas de subida e descida maiores resultaram em transferências mais regulares independente do gás de proteção utilizado. Porém, nestas condições a 
transferência é mais abrupta, provocando mais oscilações da poça de fusão.

\section{Agradecimentos}

Os autores deste trabalho gostariam de agradecer ao Laprosolda/UFU (Centro para Pesquisa e Desenvolvimento de Processos de Soldagem da Universidade Federal de Uberlândia) pelos consumíveis e infraestrutura laboratorial e ao CNPq pelas bolsas de estudo concedidas. Também gostariam de agradecem à Air Products do Brasil pelo fornecimento dos gases de proteção utilizados.

\section{Referências Bibliográficas}

[1] BAIXO, C. E. I.; DUTRA, J. C. Processo MIG/MAG: Metodologia para Determinação de Relações Paramétricas Tensão/Corrente para Transferência por Curto-Circuito. In: XVII Encontro Nacional de Tecnologia da Soldagem, 1991, Recife/PE. Anais do XVII Encontro Nacional de Tecnologia da Soldagem. São Paulo: Associação Brasileira de Soldagem, 1991. p. 265-283.

[2] KOBAYASHI, Y; ANASTÁCIO, A. C. S. A.; NARDI, C. Estudo da Influência da Variação da Corrente de Curto-Circuito, Através da Indutância, sobre as Características Geométricas e Rendimento Real de Deposição. In: $3^{\circ} \mathrm{COBEF}, 2005$, Joinville SC. Anais do $3^{\circ}$ Congresso Brasileiro de Fabricação. CD-ROM. [3] SILVA, H. R.; FERRARESI, V. A. Influência dos Parâmetros de Soldagem MIG de Alumínio na Qualidade do Cordão de Solda. Soldagem \& Inspeção, São Paulo, Volume 8, nº 1, p. 3945, Mar 2003.

[4] ZIELINSKA, S.; PELLERIN, S.; DZIERZEGA, K.; MUSIOL, K.; IZARRA, DE CH.; BRIAND, F. Gas Influence on the Arc Shape in MIG-MAG Welding. The European Physical Journal Applied Physics, Volume 43, nº 1, p. 111-122, Sep 2008. [5] STENBACKA, N.; PERSSON, K. A. Shielding Gases for Gas Metal Arc Welding. Welding Journal. Volume 68, n 11, p. 41-47, Nov. 1989.

[6] SOUZA, D.; ROSSI, M. L.; KEOCHEGUERIANS, F.; NASCIMENTO, V. C.; VILARINHO, L. O.; SCOTTI, A. Influência dos Parâmetros de Soldagem na Estabilidade do Processo MIG/MAG Operando em Curto-Circuito. In: XXXV CONSOLDA, 2009, Belo Horizonte - MG. Anais do XXXV CONSOLDA, 2009. CD ROM.

[7] DUTRA, J. C. MIG/MAG - Transferência Metálica por Curto-Circuito - Fontes de Soldagem versus Gases do Arco. Soldagem e Inspeção. São Paulo, Volume 13, n 1, p.019-024, Jan/Mar 2008.

[8] SOUZA, D.; RESENDE, A. A.; SCOTTI, A. Um Modelo Qualitativo para Explicar a Influência da Polaridade na Taxa de Fusão no Processo MIG/MAG. Soldagem e Inspeção (Impresso), v. 14, p. 192-198, 2009.

[9] SOUZA, D. Levantamento de Mapas Operacionais de Transferência Metálica para Soldagem MIG/MAG de Aço Carbono na Posição Plana. 2010. 304 f. Dissertação de Mestrado - Universidade Federal de Uberlândia, Uberlândia/MG.
[10] REZENDE, G.M.C., LISKÉVYCH, O., VILARINHO, L.O., SCOTTI, A., Avaliação de uma Metodologia para Seleção de Parâmetros em Soldagem MIG/MAG por Curto-Circuito, submetido e aceito para publicação na revista Soldagem e Inspeção. 